\title{
A Circular Economy Is About the Economy
}

\author{
Ken Webster ${ }^{1}$
}

Received: 10 March 2021 / Accepted: 16 March 2021 / Published online: 11 April 2021

(C) The Author(s) 2021

\begin{abstract}
In this paper, I outline the scope and the potential of a 'circular economy' in the future, one which goes beyond a concentration on recycling and waste management. I argue that three key elements are paramount. The first, and most widely discussed, is its 'circularity by design' characteristics. Secondly, but rarely discussed, the intimate relationship between the materials cycle and money and finance systems. Thirdly, encompassing both but often ignored: the way in which a more holistic interpretation of the concept is attached to a worldview or 'framework for thinking'. This last element is a perspective that understands the economy as less like a machine and more like a nested living system. This worldview includes a stock maintenance emphasis placed in relation to feedback-rich flows. It extends, ineluctably, to the regeneration of natural capital and the restoration of social capital. A systems perspective includes a renewed focus on creating a refreshed industrial or productive economy at all scales as opposed to an expanded extractive or 'rentier' economy which is parasitical. This is quite unlike the current, linear, economy which not only extracts and runs down natural and social capitals (or exchanges it for financial capital), but also sees surplus financial reinvested largely in existing assets rather than creating new ones. The opportunity exists to create a 'systems aware' circular economy, one which is consistent with our contemporary understanding of ecosystemic relationships, the maintenance of capitals or stocks, the interdependence of different scales and the clear distinction between effective and efficient.
\end{abstract}

Keywords Circular economy · Economics $\cdot$ Systems thinking $\cdot$ Complex adaptive systems · Rentier economy

\section{Introduction}

A circular economy must be in service to the economy as a whole, a complex task. We illustrate how easily the discussion can be misdirected (in the case of recycling) or that circular

Ken Webster

ken@circulareconomy.co.uk

1 Department of Management and Engineering (IEI), University of Linköping, SE-581 83 Linköping, Sweden 
economy initiatives might increase the extractive tendency evident in the financial/rentier * economy by encouraging the creation of new asset classes and monopoly opportunities (e.g. 'sharing economy') [10]. If unchallenged, this presents a double whammy: extractive materials and financialised, extractive economies adjusting under a circular economy banner. In terms of worldview, a circular economy might even retain an attachment to an engineered pipework rather than an ecosystemic perspective.

\section{The Logic of Recycling}

I begin with materials and illustrate the way in which recycling can misdirect their attention. The comforting logic of recycling is that valuable, durable materials can be recovered if the products and components into which they were originally made cannot be maintained, refurbished, repurposed, resold or remanufactured economically anymore. It takes energy and effort to recycle back to the original purity of the molecules, but the materials are valuable, so it will end up making economic sense. If materials belong to a biocycle, order is ultimately rebuilt via decomposition and the action of living systems; otherwise, human management of a technical material is necessary. So far, this is reasonable but appears to depend on the design including features for deconstruction, value, accessibility.

The logic of recycling is, however, misapplied. A throughput 'scale and sale' system based on short cycle, low value but durable materials cannot work except through sleight of hand. Stahel [38] and others have pointed out that even a leakage of $10 \%$ on a short cycle of say 6 weeks between creation and recovery iterates through to half the original stock of material being lost to the environment in under a year, and all of it in approximately 20 months. For low-value materials, leaning, sorting and processing do not often add up to the creation of an economic competitor to new materials. Added to that is the scourge of 'single use' and multilayered materials coupled with high volume which generates so much waste beyond recovery: rather than a meaningful resource. The notion of recycling, of 'closing the loop' and making things 'whole', in this context may always have been a distraction technique as Heather Rogers [35] claimed in her film Gone Tomorrow: The Hidden Life of Garbage. The technique that she highlighted was to shift attention on the issue from producer to consumer in respect of the impact of no deposit packaging especially aluminium cans and later plastic bottles and bags. Rogers and Parenti [34] noted:

Ultimately, the environmental crisis, of which garbage is just a subset, is inseparable from the logic of our whole economic system.

If a given, or the logic, as Rogers [35] terms it, is the large-scale production facility and centralised distribution which lead to limited options. Accepting quality recovered materials is fine in theory so long as the material fits the existing production process and is competitive on price. Since there are significant investments by the suppliers of the virgin (fossil fuel) raw materials in these facilities (or they are owned by them), a closed loop is unlikely.

The remaining surplus of recovered materials, often contaminated and mixed, could be diverted to landfill or incineration or to 'recycling' in Asia, especially China until 2017 [21]. Labour costs were low and regulation limited or poorly enforced. Shipping containers were often empty on the return from the USA or Europe, so it was a cheap option. It is still a linear economy with, at best, a detour to incineration, landfill or the oceans.

It seems something similar is happening today under the banner of circular economy. Hopes of chemical recycling or of waste gasification are high [23]. Incineration, on the basis 
that there is a 'recovery'(energy recovery), is also sometimes lumped under a circular economy heading [43]. Diversified sourcing of PET from plant material is happening [47], but the issue of reprocessing remains the same. At the same time, a widespread public sensitivity to ocean contamination has emerged [3] and consumer lifestyles seem to be changing. One of these changes is counterproductive; the rise of fast fashion has amplified waste streams so that this 'people packaging' joins product packaging as increasingly disposable. While the availability of Asian countries to deal with the very low-grade municipal waste material has been diversified as China rejects material imports, it is also contracting, and increasingly significant flows of discarded apparel are underway in the same direction. Looking at the bigger picture, apparel and product packaging account for nearly $50 \%$ of total plastics production [33]. This is a marker for the size of the role of disposable packaging.

Coincidentally, the 'fracking' boom, the exploitation of oil and gas in shale formations, increased the amount of gas and oil fractions suitable for petrochemicals and at very low cost. Ironically, fracking is an industry that has lost $\$ 280$ billion [13] in its first 10 years. So, in effect, it has been enjoying a subsidy from investors [1]. Again, the logic of the economic system remains firmly linear even as it adapts. In a recent report by Changing Markets Foundation on Fossil Fashion [17] noted:

The oil and gas industry is betting big on plastics, from which polyester and synthetic

fibres are made, as revenue from other sectors, such as transport and energy, declines

A circular economy approach in the context of increased sector growth might be seen as a commitment to creating more recovered but pure materials from mixed plastics, for example, in the multicycle process [28] and other forms of chemical recycling. The key here is scale and continuity with established business.

This side by side graphic from McKinsey makes it look like great strides are possible but underlying it is the huge increase in the market for polymers so net gains are thin or absent. It also depends on some crucial regulatory change and oil prices at $\$ 75$ a barrel (that is $20 \%$ above where they are now Feb 2021) (Figs. 1 and 2):

It seems even innovative approaches to product and material recovery are swamped by increasing virgin material supply and growing market demand, underlaid by subsidies. Once more, it might be argued that the potential of a circular economy is more something to talk about and agree with than to achieve at scale. Partly because, first of all, scale and sale are key drivers in production; secondly, materials, labour inputs and energy do not reflect full costs and, finally, the material choices (especially plastics) are ill-suited to being a 'product of consumption' (biodegradable) if extended use is for all intents and purposes factored out.

\section{Moving Beyond Recycling}

The need for appropriate product, component and material design is frequently discussed [22]. It has perhaps never been a more important time to question the most appropriate materials for packaging and textiles, to enable them to be 'nutrients' for the system. It is not in the scope of this position paper to address this, except to note that the process is often informed by the use of insights from living systems [8]. The role of a suitable 'framework for thinking' takes centre stage now as it allows the links between products, material and money stocks, flows and feedback to find common ground, in short, a more inclusive view of the economy [44]. 


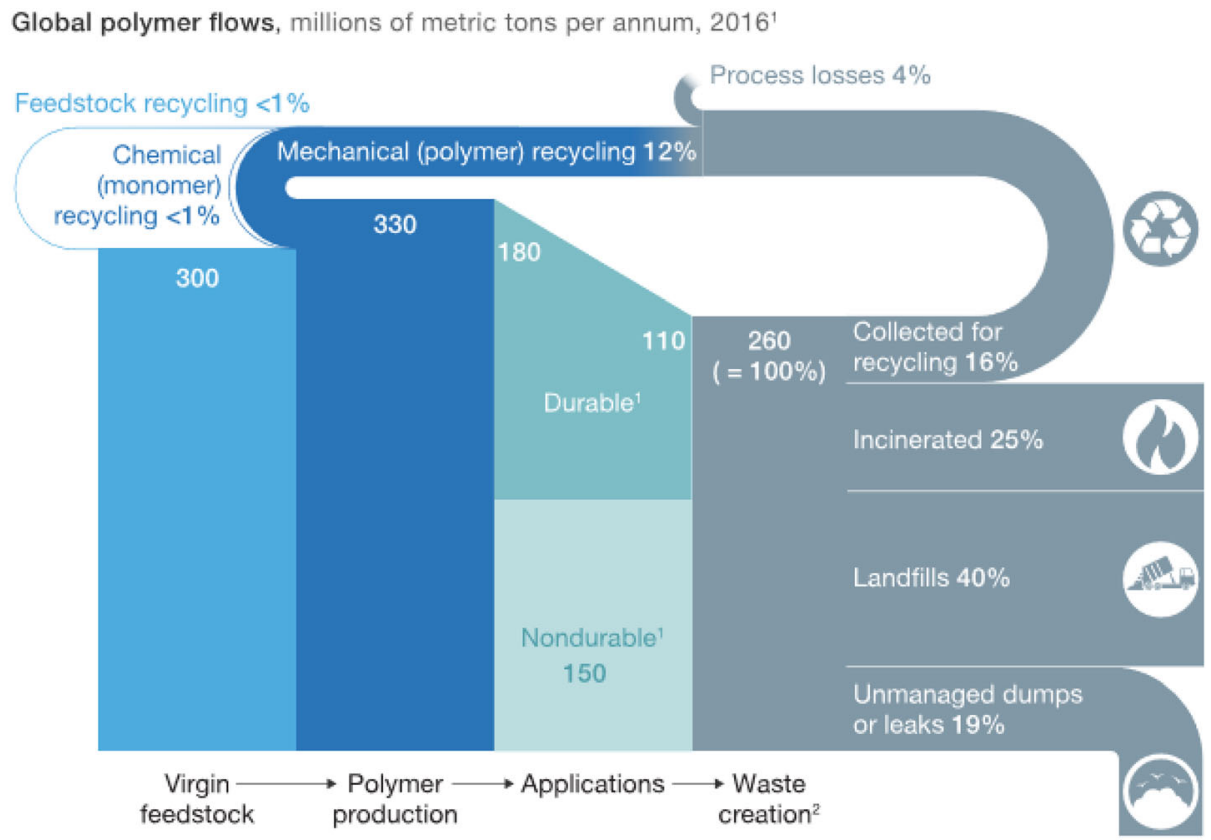

'Durable applications with an average lifetime $>1$ year will end up as waste only in later years; nondurable applications go straight to waste.

${ }^{2} 150$ million metric tons of mixed plastic waste from nondurable applications that end up as waste in same year, plus 110 millian metric tons of mixed plastic waste from production in previous years.

Fig. 1 Global polymer flows from Hundertmark et al. [20]

Most abstract thought is highly metaphorical [30]. It is no mere flourish of language and, therefore, to describe the circular economy in a more engaging and realistic way, one could look for insights in the way organisms function within ecosystems [46]. If it is useful and, moreover, consistent with the contemporary science of complex systems, it is highly likely to become mainstream thinking over time [24].

The fall out may eventually be an economic narrative which is eminently suited to the economic challenges of the current day: focusing on the notion of circulation (rather than extraction) at all scales, whilst restoring, rebuilding and maintaining capitals. The focus moves to creating an effective and not just efficient productive (industrial) economy as opposed to the financial or rentier economy which dominates today [10].

\section{Circular Economy: Less as a Pipework and More as an Ecology}

The circular economy can be discussed more coherently using a number of insights from living systems, whether related to capital or stock maintenance, i.e. continuing the viability of the person/organism/business [15] over time or accepting that a healthy interchange between the organism and its environment is mandatory (i.e. 'waste $=$ food'). Or that diversity of culture, scale, orientation or activity adds both resilience and creativity to an economy [7]. It is no coincidence that many early writers and practitioners are all deeply rooted in this kind of thinking. Precursors are economist Kenneth Boulding or ecologist and biologist Barry 
Global waste polymer flows 2030, millions of metric tons per annum

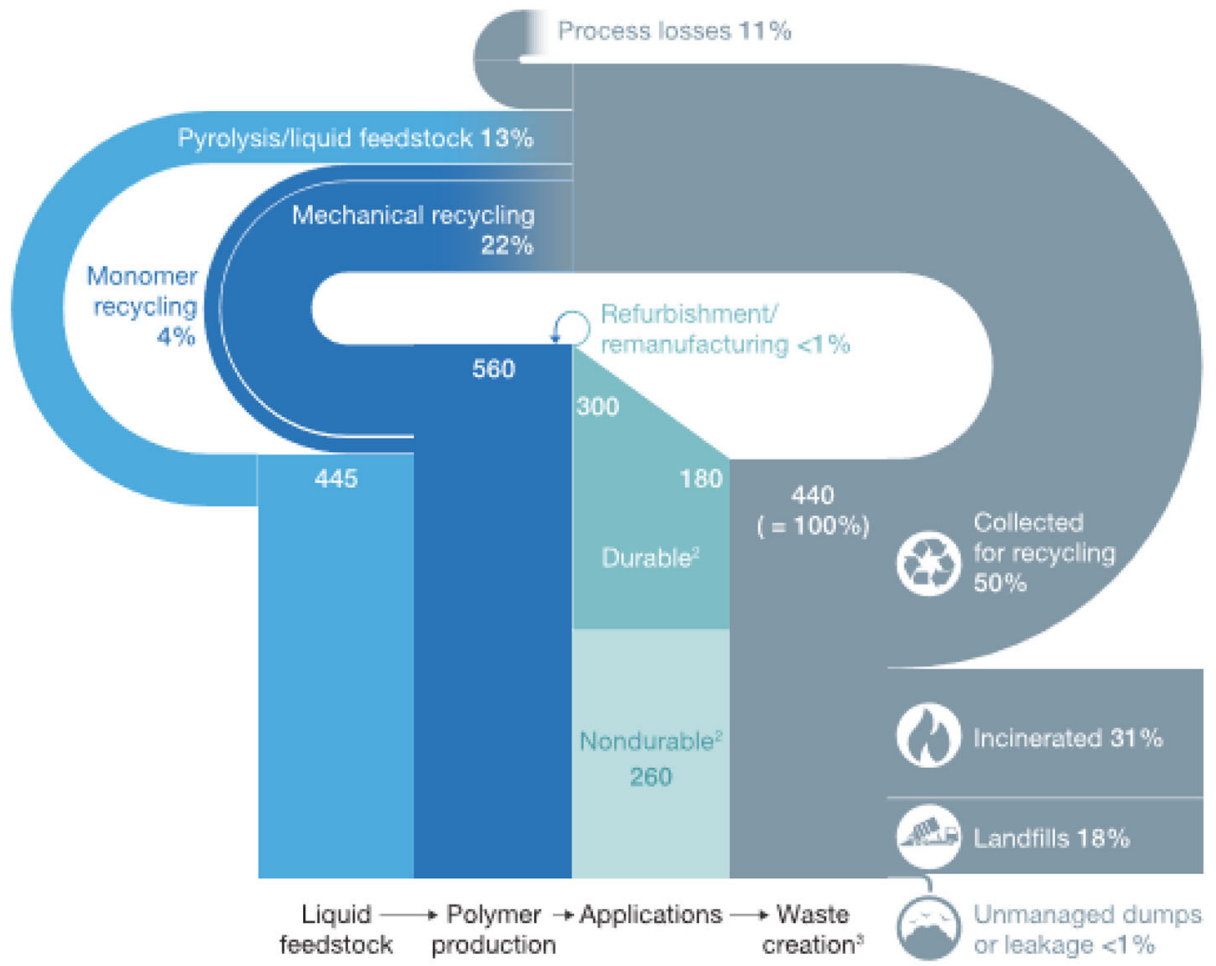

'Scenario based on a multi-stakeholder push to boost recycling, regulatory measures to encourage recycling. consistent progress on technologiss, and $\$ 75$-per-barrel oil prices.

Durable applications with an average lifetime $>1$ year will end up as waste only in later years, while nondurable applications go straight to waste.

260 million metric tons mixed plastic waste from nondurable applications that end up as waste in same year plus 180 million metric tons of mixed plastic waste from production in previous years.

Fig. 2 Global waste polymer flows in 2030 from Hundertmark et al. [20]

Commoner in the 1960/1970s and the likes of Janine Benyus, Gunther Pauli, Bill McDonough, Michael Braungart and Amory Lovins from the mid-1990s onwards. How it is manifested varies, unsurprisingly, but a 'living systems' approach is arguably one of the markers of a circular economy [5].

Such a systemic approach embraces multiple cycles, works at all scales and is intended to create an economy 'regenerative, accessible and abundant by design' [41]. A veritable ecology of businesses in fact and within that the notion of taking cues from nature rather than the machine lies a source of inspiration for many. The motivation seems to be 'an economy that works long term' [45]. It might contain a rather naïve view of nature's processes, but it appeals and advocates that 3.8 billion years of evolution represent a more than decent track record. Whether fairness is built-in depends on structural characteristics as well as political choices. Structurally, it involves looking for the effective solutions and not just efficient ones [12]. Effectiveness relates to the purpose of a system and includes the periphery as well as the core.

In a brief summation: purposeful, effective, stock maintaining, Nutrient cycling, nonlinear and interdependent at all scales. 
It does not take much introspection to recognise that efficiency, by contrast, is a relationship between input and output and does not necessarily engage with purpose or concepts such as the ability to endure or respond to shocks (resilience). It also entertains the notion of extraction. A linear economy is inherently extractive as sources, and 'sinks' are assumed to be limitless and feedback limited outside of the short term and the monetised elements. It also implies that the idea of growth is, in a narrative sense, unlimited. As efficiency creates a surplus which can be reinvested in further production and technological efforts to further improve labour and resource efficiency, including substituting different factors of production one for the other if supply is constrained. If we add in the prevailing modernist notion that humankind is in charge of the planet: the ubiquitous use of the image that the 'world is in our hands' for example and that somehow 'we can save the planet' is indicative. It carries the implication that anything can be fixed, whenever we choose. It is very much a mechanical 'linear', boundaried understanding set within an unbounded vision based on technology

\section{Financial Pollution}

Although, in theory, any surplus is assumed to be reinjected through the investment of savings into production or technological innovation, reality turns out to be different. Or rather, it happens less and less after a certain point (usually when overproduction is making thin margins) [9], and surplus in this 2nd cycle of industrial society is placed into existing assets such as real estate, stocks bonds and intellectual property [10]. This is the money cycle as extractive of value rather than creating more of it. It uses the store of value function of money and limited access to create that effect, ultimately creating unearned income or economic rent. It is scarcity-driven. Without getting into the economic detail, it is sufficient to note Frederick Soddy's [37] comment:

The ruling passion of the age is to convert wealth into debt in order to derive a permanent future income from it - to convert wealth that perishes into debt that endures, debt that does not rot, costs nothing to maintain, and brings in perennial interest.

Thus, it seems that both monetary and materials are characterised by extractive, economic rentseeking activity rather than 'circularity' or nourishing the core and periphery in a metabolistic sense. This is not a new observation, but it is interesting to note the parallel with efforts by all the classical economists from Adam Smith to the likes of Henry George and Thorstein Veblen to identify the use of free and fair markets as a tool to undermine the rentier, the landlord and banker who were otherwise able to increase their wealth without making a contribution, or as JS Mill [27] suggests 'in their sleep' (Fig. 3).

Beth Stratford [39] recently took an in-depth look at the interconnections between resourceconstrained economies and successful rent-seeking economies. She concluded that rentseeking economies reduced the amount of discretionary spending available to the majority of the population, inhibited investment in productive innovation, in favour of 'making money on money', and was a key driver of inequality. The fact that it is underwritten by governments who adopt the approach of maintaining asset values as the number one priority in times of crisis (as happened in 2008 as well as 2020 [19]) actually reinforces this tendency; the practice is therefore backstopped. In the face of low or no economic growth (except that which is prompted by the richest $10 \%$ spending some of their additional wealth), governments must reinvest in the prospect of economic growth with whatever additional means they can muster, 
Fig. 3 A critique turned on its head (Bank advertising in Australia)

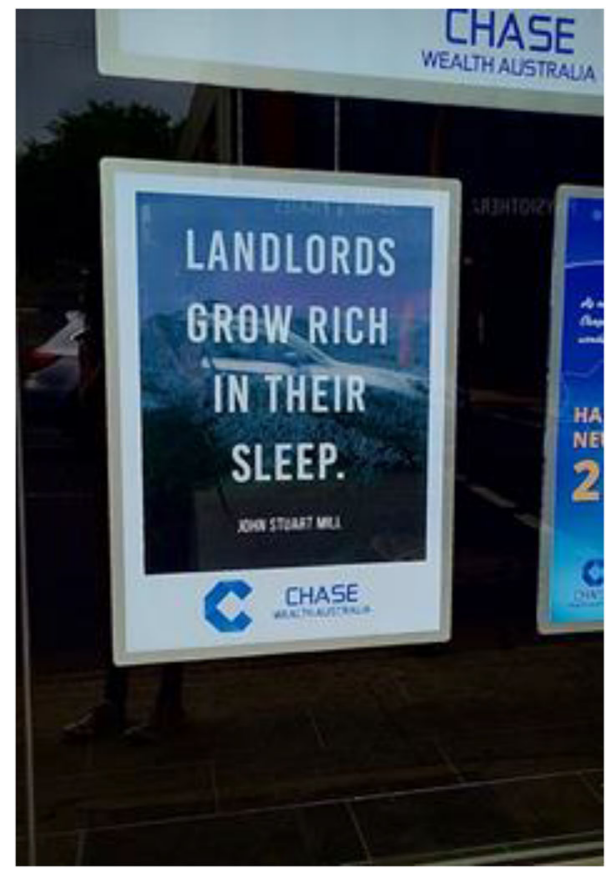

thus an ever more frenetic race for efficiency and lowered costs. As Adair Turner [42] noted in his book on the financial system Between Debt and the Devil: Money, Credit, and Fixing Global Finance, 'debt is financial pollution'. We argue it does indeed have a role parallel to the waste inherent in the materials and energy cycles in reducing the 'health' of the overall economy.

Overall, the proposal to emphasise circulation over extraction as a guiding structural principle creates a circular economy which intends, in an overarching and quite logical way, to remove or at least dampen down the extractive element. This makes the exercise into quite a radical proposition as political power resides most often according to Michael Hudson in those who control rent seeking [4].

If a circular economy points towards building an regenerative economy, as the name suggests, it should circulate materials and money to all scales with as little rent seeking as possible (within limits imposed by ecological systems). It is indeed novel and radical by today's standards. If we add in the often-heard criticism that decoupling growth from increases in energy and resource extraction is extremely difficult or impossible anyway [18], then proposals for 'degrowth' and some sort of 'thriving' economy based on other measures of economic wellbeing become heard more frequently [32] while still locating a 'circular economy' at its heart. One aspiration is for people to participate in new opportunities for social production and exchange on a more local or regional basis to create a 'foundation economy' in cooperation with the public sector [16]. A socially orientated, context-driven circular economy of this kind risks being unacceptable to some other groups at quite a visceral level. It flies in the face of expectations of a good life inculcated since the 1980s: wealth accumulation, cheap goods, hedonistic experiences, individualism and 'betterment'.

Economist Kenneth Boulding [6] insisted that an economy is composed of knowledge, energy and materials. The alternative to a metabolistic or living systems approach, as hinted at 
above, is to use familiar or novel technologies or tools to tackle the resource (energy and materials) issues. This is 'Circular economy as a toolbox' which by omission and having no deeper purpose or meaning obscures economic rent seeking by emphasising an acceptable or less threatening version of a circular economy directed towards the growth imperative. Knowledge is focussed on technology, business and related sciences not moral philosophy or political economy or indeed history.

The intelligent observer will, however, recognise that the viability of a linear economy is declining from the impact of carbon emissions and on supporting ecosystems, especially biodiversity. A restless impatience from consumers and citizens and many governments also do not bode well for cavalier high-carbon producers. For some, the medium range challenges around accessing critical raw materials weigh heavily, and for others, the aging demographic and marginal returns from manufacturing mass-produced goods in many sectors - electronics, tools and through to clothing and household goods - beg the question of how to maintain or increase revenue when markets are saturated. This brings us to the use of a general shift from products to services, or access over ownership and how it might play out in this context. It is set within an economy with fewer key industry players than in recent decades.

Digital transformations have unlocked a number of potentials. Firstly, to reconfigure the notion of products as services for the twenty-first century now that monitoring and billing for the use of equipment, from vehicles to washing machines to heating and ventilation/air conditioning, can be sliced and diced and much of the technology gets cheaper as it gets more general purpose and scales up. The retention of the product as an asset potentially adds new asset classes to the more traditional categories outlined above and coupled with the logic of ideas such as 'total product liability' where the manufacture retains ownership or acts as if they do [11] links reducing environmental impact to better design, more intelligent use phases (the supply of feedback and checking of optimal functionality) and further industry consolidation or collaboration across the value chain. This is no place for the peripheral player.

A related development has been the 'sharing economy' in which higher rates of utilisation of existing objects (usually owned by a multitude of people) can be imagined. In addition to this, it has the benefit of controlling the digital platforms which facilitate this exchange, and/or rental activity is highly sought as a means of establishing a monopoly or near-monopoly. It has been a prompt for predatory pricing to 'disrupt' the industry sector in the initial phases. An example of these ideas in practice includes ride hailing where Uber and Lyft in the USA comprise $98 \%$ of the market [48]. Again, this is no place for the smaller player unless regulatory measures (antitrust) resist the changes [29]. Metcalfe's law of networks (the number of connections is the square of the number of nodes) does indicate that the benefits of networks scale rapidly and militate against smaller operators [14].

As evidence of the potential of a number of these shifts, it is easy to identify what the major business consultancies are selling as business opportunities in the circular economy arena. Accenture is leading this with their Five Business Models (Circular Advantage [25]). Three out of five business models are digitally orientated and conform to the general outline sketched in the preceding paragraphs: more revenue from less throughput. Product life extension can fall out of product as service as well as conventional sales and maintenance contracts, remarketing and repair, for example.

There are also the material recovery and 'circular supplies' categories in Accenture's proposed business models. This material supply and recovery loop is often better labelled as the 'recycling economy' [31], as something of an interim arrangement between a linear and circular economy. We have examined above how this is not suited to low-value, short-cycle products unless they belong to the biocycle. 


\section{Conclusion}

The overall result of the three shifts discussed above (circularity by design, the intimate relationship between the materials cycle and money and finance systems and the way the holistic interpretation is connected to a worldview or 'framework for thinking') might be viewed as positive if described as a direction of travel. A circular economy cannot be expected to be delivered ready-made out of the box. Certainly, a changed framework for thinking is one way of accelerating action as fully formed, and applied, it becomes a guiding narrative, much as the machine-world framework did for nineteenth century science and by imitation, economics. However, wrong-headed material recovery adds support to the advocates of recycling even when the basic mathematics is still hopeless: The legacy issue of poor materials choices in the past could be increasingly divorced from an approach which designs out many of the problems inherent in 'disposable' durable materials. The former has little to inform the latter. On the product to service shift (extended product life and access over ownership particularly) then the value in networks at scale is legitimising, as it were, further concentration of business and industry under a rentier umbrella. If, as expected, significant and durable products, components and materials become assets, then it is also likely to be successful in reducing resource use in the medium term, once a monopoly or oligopoly structure has settled.

The risk, however, of having change which reinforces the rent-seeking without enabling the sort of centre and periphery or overall participatory economic opportunities promised by the same technologies is very real. At the extreme, a kind of neo-feudalism in which everything significant is owned by very few and users, unless well protected by laws around contract, division of responsibility and freedom of access are supplicants and not even customers. The development of a circular economy, using the idea of open platforms, cascading materials and repurposing, often upcycling products and components, could enable more social production on a distributed or peer-to-peer-basis. These activities create in Michel Bauwens terms 'Schools of Democracy' [40] due to the meaningful coming together around a shared purpose rather than the individualised consumer left with a restricted power to choose, a supplicant as a platform user and as a gig economy contractor when it comes to employment. Paul Mason [26] characterised the tensions of a postmodern age in this snapshot:

The key contradiction of modern capitalism is between this emerging possibility of free socially produced abundant goods and a system of monopolies, banks and governments forced to behave desperately to maintain information asymmetry. That is, everything is pervaded by a fight between network and hierarchy

There is every reason to assume that the notion of a circular economy can be found as part of this 'fight', on both sides. It is clear that the place of a circular economy in an economic system described through the lens of metabolistic and effective, all-scale living systems would be one that gave due weight, and a solid rationale to the inclusion of a vibrant 'network' (in Mason's terms) as a necessary component around which investment could be delivered. An economy writ large would benefit from the deployment of this rounded circular economy framework as it is based on a scientific appreciation of the nature of effective systems as an interplay between efficiency and resilience. This runs contrary to mainstream thinking which is focussed on technical and supply sided changes which leave political arrangements and their economic underpinning largely intact. Perhaps this is inevitable: the principal attraction for many in business and policy circles is exactly the way in which a circular economy can be seen as an economic opportunity driven by innovation. And if an 'economic opportunity' slides into 
being a business opportunity and innovation, a function of digital technology so much the better in terms of its uptake. But equally, if it is a systems perspective, then there is yet more to be explored, and there is no reason it cannot also contribute to increased well-being.

\section{Discussion and Limitations}

As someone who has worked in the context of a systems approach to the circular economy for a decade or more, this paper is a reflection on some of the ways in which I have seen the discussion shift. It is more than anything a call for more interdisciplinary (academic) work. Currently, the tendency is to silo the discussion, a not uncommon approach to any area of study. The discussion around a circular economy requires a more systemic perspective in contradiction to some of the more traditional areas of study.

An umbrella term like 'circular economy' can encompass many related ideas, and more effort at synthesis would be rewarding, especially if the recognition increases around the kinds of systems that require studying are often complex adaptive systems and that studies based on assumptions of long-term equilibrium and tightly scoped agents are left behind.

The rentier class generates income (or rent) through the ownership and control of scarce assets, such as credit money, shares, real estate, natural resources, radio spectrum and intellectual property. Big rentiers include commercial banks, institutional investors, property developers, energy corporations, telecommunication companies and natural monopolies. Petty rentiers include ordinary savers, individual shareholders, small landowners and local hoteliers. Rentierism is a diverse, complex and variegated process, and the state plays a key role in how it unfolds in specific moments ([10]; Andreucci et al. [2, 36]).

Acknowledgements I would like to acknowledge the important contributions made to this paper by Emma $\mathrm{H}$. E. Fromberg from the University of Cambridge Institute for Sustainability Leadership.

Funding Open access funding provided by Linköping University. Created as part of the author's attachment to the University of Linköping.

\section{Declarations}

Additional declarations for articles in life science journals that report the results of studies involving humans and/ or animals

Conflict of Interest The authors declare no competing interests.

Open Access This article is licensed under a Creative Commons Attribution 4.0 International License, which permits use, sharing, adaptation, distribution and reproduction in any medium or format, as long as you give appropriate credit to the original author(s) and the source, provide a link to the Creative Commons licence, and indicate if changes were made. The images or other third party material in this article are included in the article's Creative Commons licence, unless indicated otherwise in a credit line to the material. If material is not included in the article's Creative Commons licence and your intended use is not permitted by statutory regulation or exceeds the permitted use, you will need to obtain permission directly from the copyright holder. To view a copy of this licence, visit http://creativecommons.org/licenses/by/4.0/. 


\section{References}

1. A fracking great Ponzi scheme (2019) Electrical Review. Retrieved from: https:/electricalreview.co.uk/ 2019/09/10/a-fracking-great-ponzi-scheme/. Accessed 08 Apr 2021

2. Andreucci D, García-Lamarca M, Wedekind J, Swyngedouw E (2017) Value grabbing: A political ecology of rent. Capitalism Nature Socialism, 28(3):28-47. https://doi.org/10.1080/10455752.2016.1278027

3. Barrowclough D, Deere Birkbeck C (2020) Transforming the global plastics economy. Global Economic Governance Programme

4. Bezemer D, Hudson M (2016) Finance is not the economy: reviving the conceptual distinction. J Econ Issues 50(3):745-768

5. Borrello M, Pascucci S, Cembalo L (2020) Three propositions to unify circular economy research: a review, Sustainability, MDPI. Open Access J 12(10):1-1 May.

6. Boulding KE (1978) The future of the interaction of knowledge, energy, and materials. Behav Sci Res 13(3):169-183

7. Braungart M, McDonough W (2002) Cradle-to-cradle design: creating healthy emissions-a strategy for ecoeffective product and system design.

8. Capra F, Luisi PL (2014) The systems view of life: a unifying vision. Cambridge University Press. Circular Advantage: innovative business models and technologies to create value in a world without limits to growth (2014) Accenture. Retrieved from: https://www.accenture.com/t20150523T053139_w_/us-en/_ acnmedia/Accenture/Conversion-Assets/DotCom/Documents/Global/PDF/Strategy_6/Accenture-CircularAdvantage-Innovative-Business-Models-Technologies-Value-Growth.pdf. Accessed 08 Apr 2021

9. Christophers B (2011) Revisiting the urbanization of capital. Ann Assoc Am Geogr 101(6):1347-1364

10. Christophers B (2020) Rentier capitalism: who owns the economy, and who pays for it? Verso

11. Domenech T, Ekins P, van Ewijk S, Spano Klein C, Kloss B, Miedzinski M, Petit M, Stuchtey M, Tomei J (2019) Making materials work for life - introducing producer ownership. LAUNCH. Retrieved from: https:// www.systemiq.earth/wp-content/uploads/2020/02/Producer-Ownership-Project-LAUNCH-White-Paper. pdf. Accessed 08 Apr 2021

12. Fath BD, Fiscus DA, Goerner SJ, Berea A, Ulanowicz RE (2019) Measuring regenerative economics: 10 principles and measures undergirding systemic economic health. Glob Transit 1:15-27

13. Finances of fracking: shale industry drills more debt than profit (2020) Retrieved from: https://www. desmogblog.com/finances-fracking-shale-industry-drills-more-debt-profit. Accessed 08 Apr 2021

14. Fisk P. (2020) Metcalfe's Law explains how the value of networks grows exponentially Retrieved on 25/05/ 2020 from https://www.thegeniusworks.com/2020/02/metcalfes-law-explains-how-the-value-of-networksgrow-exponentially-there-are-5-types-of-network-effects/. Accessed 08 Apr 2021

15. Fromberg EHE (2020) Three forgotten lessons about the circular economy. The Mint Magazine Retrieved from: https:/www.themintmagazine.com/three-forgotten-lessons-about-the-circular-economy. Accessed 08 Apr 2021

16. Foundational Economy (2021) Retrieved from: https://foundationaleconomy.com/introduction/. Accessed 08 Apr 2021

17. Fossil fashion: the hidden reliance of fast fashion on fossil fuels (2021) Changing Markets Foundation. Retrieved from: http://changingmarkets.org/wp-content/uploads/2021/01/FOSSIL-FASHION_Webcompressed.pdf. Accessed 08 Apr 2021

18. Hickel J, Kallis G (2020) Is green growth possible? New Polit Econ 25(4):469-486

19. Hudson, M. (2020) FED's $\$ 10$ Trillian defends assets of the rich. Retrieved from: https://theanalysis.news/ interviews/feds-10-trillion-defends-assets-of-the-rich-michael-hudson/. Accessed 08 Apr 2021

20. Hundertmark T, Mayer M, McNally C, Simons TJ, Witte C (2018) How plastics waste recycling could transform the chemical industry. McKinsey \& Company Retrieved from: https:/www.mckinsey.com/ industries/chemicals/our-insights/how-plastics-waste-recycling-could-transform-the-chemical-industry\#

21. Katz C (2019) Piling up: how China's ban on importing waste has stalled global recycling. Yale Environ: 360 Retrieved from: https://e360.yale.edu/features/piling-up-how-chinas-ban-on-importing-waste-hasstalled-global-recycling. Accessed 08 Apr 2021

22. Kirchherr J, Reike D, Hekkert M (2017) Conceptualizing the circular economy: An analysis of 114 definitions. Resour Conserv Recycl 127:221-232

23. Krause L, Dietrich F, Skoczinski P, Carus M, Ruiz P, Dammer L, Raschka A (2020) Chemical recycling status, trends and challenges. Retrieved from L https://renewable-carbon.eu/publications/product/chemicalrecyclingstatus-trends-and-challenges-technologies-sustainability-policy-andkey-players/. Accessed $08 \mathrm{Apr}$ 2021

24. Kuhn TS (1962) The structure of scientific revolutions. University of Chicago press 
25. Lacy P, Keeble J, McNamara R, Rutqvist J, Eckerle K, Haglund T, Buddemeier P, Cui M, Sharma A. Cooper A., Senior T, Pettersson C (2014) Circular Advantage: Innovative business models and technologies to create value in a world without limits to growth. London, UK: Accenture

26. Mason P (2016) Postcapitalism: a guide to our future. Macmillan

27. Mill JS (1848) On liberty and other writings. Cambridge University Press

28. Multicycle - overview (2021) Retrieved from: http://multicycle-project.eu/\#overview. Accessed 08 Apr 2021

29. Philippon T (2019) The economics and politics of market concentration. National Bureau of Economic Research Retrieved from: https://www.nber.org/reporter/2019number4/economics-and-politics-marketconcentration. Accessed 08 Apr 2021

30. Lakoff G, Johnson M (2008) Metaphors we live by. University of Chicago press

31. Lemille A (2019) For a true circular economy, we must redefine waste. World Economic Forum Retrieved from: https://www.weforum.org/agenda/2019/11/build-circular-economy-stop-recycling/. Accessed 08 Apr 2021

32. Raworth K (2017) Doughnut economics: seven ways to think like a 21st-century economist. Chelsea Green Publishing

33. Ritchie, H. (2018). Our World in Data FAQs on plastic. Retrieved from: https://ourworldindata.org/faq-onplastics\#which-sectors-use-the-most-plastic. Accessed 08 Apr 2021

34. Rogers, H., Parenti, C. (2002) The hidden life of garbage: why waste keeps growing. Retrieved from: https://www.utne.com/community/the-hidden-life-of-garbage. Accessed 08 Apr 2021

35. Rogers H (2006) Gone tomorrow: the hidden life of garbage. The New Press

36. Sanghera B, Satybaldieva E (2020) The other road to serfdom: the rise of the rentier class in post-Soviet economies. Soc Sci Inf 59(3):505-536

37. Soddy, F. (1926). Wealth, Virtual Wealth, and Debt.

38. Stahel W (2010) The performance economy. Springer

39. Stratford B (2020) The threat of rent extraction in a resource-constrained future. Ecol Econ 169:106524

40. Sylvester-Bradley O, Bauwens M (2017) Representation is no longer enough. Retrieved from: https://www. opendemocracy.net/en/representation-is-no-longer-enough-qa-with-michel-bauwens/. Accessed 08 Apr 2021

41. Towards a Circular Economy (2013) Ellen MacArthur Foundation. Retrieved from: https://www. werktrends.nl/app/uploads/2015/06/Rapport_McKinsey-Towards_A_Circular_Economy.pdf. Accessed 08 Apr 2021

42. Turner A (2017) Between debt and the devil: money, credit, and fixing global finance. Princeton University Press

43. Tüttö, K. (2017) The role of waste to energy in a circular economy. The European Commission

44. Webster K (2015) The circular economy: a wealth of flows. Ellen MacArthur Foundation Publishing

45. Webster K (2016) The circular economy is part of the irresistible unfolding of a digital revolution. Circulate News Retrieved from: https://medium.com/circulatenews/the-circular-economy-is-part-of-the-irresistibleunfolding-of-a-digital-revolution-6b39a9d5a0df. Accessed 08 Apr 2021

46. Webster K, Fromberg EHE (2020) Lessons from aspects of systems thinking for an effective cross-scale circular economy

47. What is PlantBottle Packaging? (2021) Retrieved from: https:/www.coca-colacompany.com/faqs/what-isplantbottle-packaging. Accessed 08 Apr 2021

48. Yeo L (2021) Uber vs. Lyft: Who's tops in the battle of U.S. rideshare companies. Second Measure Retrieved from: https://secondmeasure.com/datapoints/rideshare-industryoverview/\#: :text=The\% 20breakdown\%20of\%20December\%20sales. Accessed 08 Apr 2021 